\title{
Palaeolithic seafaring in East Asia: testing the bamboo raft hypothesis
}

Yousuke Kaifu ${ }^{1, *}$, Chih-hsing Lin $^{2}$, Akira Goto ${ }^{3}$, Nobuyuki Ikeya ${ }^{4}$, Masahisa Yamada ${ }^{5}$, Wei-Chuan Chiang ${ }^{6}$, Masaki Fujita ${ }^{1}$, Koji Hara ${ }^{7}$ Toiora Hawira ${ }^{8}$, Kuo-en Huang ${ }^{2}$, Chih-huei Huang, Yoshimi Kubota $^{10}$, Chiung-hsi Liu ${ }^{11}$, Kumino Miura ${ }^{1}$, Yasumasa Miyazawa ${ }^{12}$, Osamu Monden ${ }^{13}$, Minoru Muramatsu ${ }^{14}$, Yunkai Sung ${ }^{15}$, Katsuaki Suzuki ${ }^{16}$, Nobuyuki Tanaka ${ }^{17}$, Cheng-hwa Tsang ${ }^{18}$, Saki Uchida ${ }^{8} \&$ Pi-ling Wen ${ }^{2}$

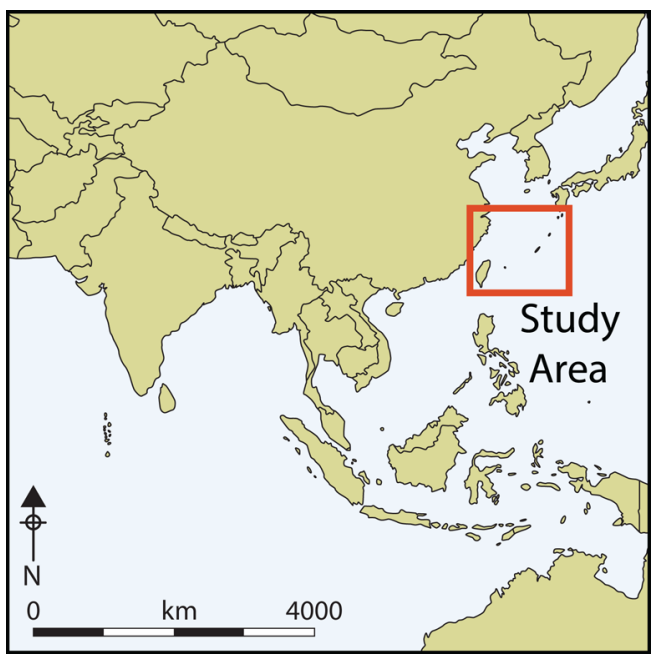

The earliest colonisation of oceanic islands by Homo sapiens occurred 50 000-30000 years ago in the Western Pacific, yet how this was achieved remains a matter of debate. With a focus on East Asia, the research presented here tests the hypothesis that bamboo rafts were used for these early maritime migrations. The authors review the evidence for Palaeolithic seafaring in East Asia as the context for an experimental archaeology project to build two bamboo watercraft. Sea trials demonstrate the unsuitability of bamboo, at least in East Asia, indicating that more sophisticated and durable vessels would have been required to traverse the Kuroshio Current.

Keywords: East Asia, Late Pleistocene, bamboo raft, watercraft, maritime migration

* Author for correspondence (Email: kaifu@kahaku.go.jp)

1 Department of Anthropology, National Museum of Nature and Science, 4-1-1 Amakubo, Tsukuba, Ibaraki 305-0005, Japan

2 Department of Exhibition and Education, National Museum of Prehistory, 1 Museum Road, Taitung 95060, Taiwan

3 Department of Anthropology and Philosophy, Nanzan University, 18 Yamazato-cho, Showa-ku, Nagoya, Aichi 466-8673, Japan

4 Center for Obsidian and Lithic Studies, Meiji University, 3670-8 Daimon, Nagawa, Chiisagata, Nagano 386-0601, Japan

5 Graduate School of Humanities, Tokyo Metropolitan University, 1-1 Minami-Osawa, Hachioji-shi, Tokyo 192-0397, Japan

(C) Antiquity Publications Ltd, 2019. This is an Open Access article, distributed under the terms of the Creative Commons Attribution licence (http://creativecommons.org/licenses/by/4.0/), which permits unrestricted re-use, distribution, and reproduction in any medium, provided the original work is properly cited.

ANTIQUITY 93372 (2019): 1424-1441

https://doi.org/10.15184/aqy.2019.90 


\section{Introduction}

The development of seafaring in the Late Pleistocene opened up new environments for Homo sapiens. It allowed our species to expand into habitable territories beyond the continental landmasses, facilitating the exploitation of marine resources, the movement of goods and social interactions (Anderson 2010). The great demands of constructing and maintaining seagoing craft (Erlandson \& Braje 2015) mean that the emergence of seafaring is intriguing from the broader perspective of behavioural economics. Regardless, our understanding of early human seafaring remains a matter of conjecture, not least because of the lack of physical evidence of Pleistocene watercraft.

The earliest reliable evidence for repeated, and thus apparently systematic and planned, sea crossings by $H$. sapiens is the appearance of archaeological sites in Wallacea (eastern Indonesia) and Sahul (Australia and New Guinea), dating to $47000 \mathrm{cal}$ BP or earlier (Clarkson et al. 2017; Kealy et al. 2018; O’Connell et al. 2018) (Figure 1). Most researchers surmise that bamboo rafts of some form were used for these earliest maritime migrations based on the availability of local materials and the inferred undeveloped wood-working technologies required to make logboats (Birdsell 1977: 143; Thorne \& Raymond 1989: 39; McGrail 2001: 288; Anderson 2010: 6; O'Connor 2010: 48). This hypothesis, however, remains to be tested. While bamboo rafts, for example, can be used in seawater, the effectiveness of such craft for long-distance voyages is unknown. Bamboo rafts with oars or paddles had been used by fishermen around the South China Sea and Taiwan, but only in rivers and shallow coastal waters (McGrail 2001). Although bamboo rafts equipped with sails and centreboards could travel for long distances (Doran 1971; Severin 1994), such craft are thought to be a Mid-Holocene invention (McGrail 2001). Bednarik's (1999) experimental research, for example, demonstrates that a bamboo raft with a simple sail could drift for more than $800 \mathrm{~km}$,

6 Eastern Marine Biology Research Center of Fisheries Research Institute, 22 Wuquan Road, Chenggong, Taitung 961, Taiwan

7 Setouchi Traditional Voyaging Society, 2056-2 Saga, Hiraoi-cho, Kumage-gun, Yamaguchi 742-111, Japan

37 Campbell Street, Whanganui 4500, New Zealand

9 Institute of Ethnology, Academia Sinica, 128 Academia Road, Section 2, Nankang, Taipei 11529, Taiwan

10 Department of Geology and Paleontology, National Museum of Nature and Science, 4-1-1 Amakubo, Tsukuba, Ibaraki 305-0005, Japan

11 Department of Life Science, National Taitung University, 684 Section 1, Chunghua Road, Taitung 95092, Taiwan

12 Application Laboratory, Japan Agency for Marine-Earth Science and Technology, 3173-25 Showa-machi, Kanazawa-ku, Yokohama, Kanagawa 236-0001, Japan

13 Studio UMI, Inc., 2-7-4-401 Osaki, Shinagawa, Tokyo 141-0032, Japan

14 Yonaguni Town Board of Education, Yonaguni, Okinawa, Japan

154 F No.6 304 Lane Anle Road, Yonhe District, New Taipei City 234, Taiwan

16 Hirumano-Nagareboshi, 46 Chojushinden Maisaka, Hamamatsu, Shizuoka 431-0212, Japan

17 Department of Botany, National Museum of Nature and Science, 4-1-1 Amakubo, Tsukuba, Ibaraki 305-0005, Japan

18 Institute of Anthropology, National Tsing Hua University, 101 Section 2, Kuang-Fu Road, Hsinchu 30013, Taiwan

(C) Antiquity Publications Ltd, 2019 


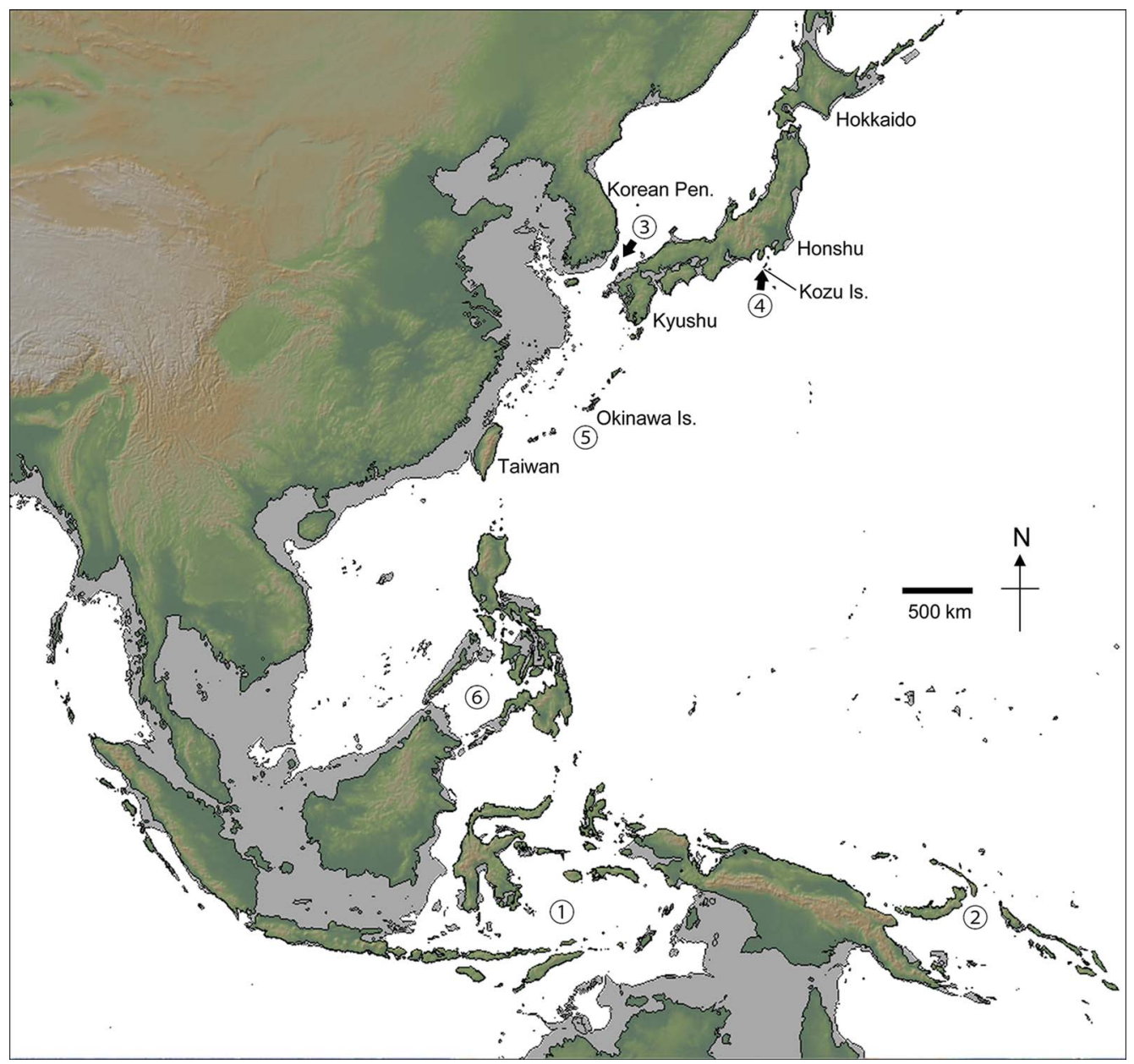

Figure 1. The Western Pacific area with evidence for Palaeolithic sea crossings: 1) Wallacea (eastern Indonesia) (>47 ka); 2) the Bismarck and Solomon Archipelagos (c. 43 ka); 3) the Korea Strait (c. 38 ka); 4) Kozushima Island (c. 38 ka); 5) the Ryukyu Archipelago (c. 35 ka); 6) the Philippine Archipelago (figure created using the GeoMapApp software (http://www.geomapapp.org)).

from Timor to Australia, with favourable winds and currents (Bednarik 1999). It is doubtful, however, whether such a one-way drifting (or gambling, as in risk vs reward drifting) method could explain the entire journey of early humans from Sunda to Sahul (that is, between the Southeast Asian and Australian continental shelves). Yet even if the bamboo raft hypothesis is correct for Wallacea (the island region between these continental shelves), other regions may have had different developmental trajectories in seafaring that deserve dedicated investigation.

To advance this debate, in 2013, we initiated a new experimental programme called 'Holistic Re-enactment Project of the Voyage 30000 Years Ago', organised by the National Museum of Nature and Science in Tokyo and the National Museum of Prehistory in Taiwan (http:/www.kahaku.go.jp/research/activities/special/koukai/). This project focuses on East Asia, where seafaring began approximately 38 000-35 000 years ago in at least three different (C) Antiquity Publications Ltd, 2019 
coastal areas (Figure 1) (Kaifu et al. 2015a). This is more than 10000 years later than the earliest example known from Wallacea, but more than 20000 years earlier than the other established cases of Upper Palaeolithic seafaring in the Mediterranean and the Americas (Erlandson et al. 2011; Phoca-Cosmetatou \& Rabett 2014). In East Asia, numerous welldated Pleistocene and Holocene sites located on offshore islands, along with their relatively abundant archaeological materials, offer us a useful framework for understanding the development of local seafaring.

This article reviews the prehistory of seafaring in East Asia, before testing whether the bamboo-raft hypothesis could explain Palaeolithic maritime migration in this region. Through the experimental construction and sea trialling of bamboo rafts, we aim to assess whether such crafts could have played a role in early East Asian seafaring, or whether other types of seagoing vessels were required for such journeys.

\section{Background}

\section{Palaeolithic seagoing crafts in East Asia}

Around the date of the initial maritime migrations in East Asia, c. 40 000-30 000 cal BP, sea levels were approximately $80 \mathrm{~m}$ lower than those today (Figure 1 ). The dates and distribution of all of the more than 10000 Upper Palaeolithic sites in the Japanese archipelago demonstrate that the earliest maritime migration in East Asia occurred about $38000 \mathrm{cal}$ BP across the strait between the Korean Peninsula and Kyushu (Kaifu et al. 2015a). Of similar date is an assemblage of obsidian artefacts recovered from Kozushima, a small island located approximately $38 \mathrm{~km}$ from Honshu during the Late Pleistocene (Figure 1); the obsidian was sourced from Honshu and the assemblage can therefore be regarded as the world's oldest secure evidence of a planned maritime voyage (Ikeya 2015). Well-dated sites located on six different islands of Ryukyu indicate that this $1200 \mathrm{~km}$-long island chain had been colonised almost entirely by $30000 \mathrm{cal}$ BP (Figure 2), with archaeological, human skeletal and genetic evidence suggesting that different parts of the island chain were colonised by different populations from both the south and north (Shinoda \& Adachi 2013; Kaifu et al. 2015b).

The evidence for seafaring becomes more widespread in the Jōmon period in Japan (c. $16000-2800$ cal BP). Occupation on Hachijyojima Island, located more than $180 \mathrm{~km}$ from Honshu, for example, began by 5000 cal BP (Oda 2000). Simple logboats, or dugout canoes, were probably used for such voyages. More than 160 Jōmon-period watercraft have been discovered to date and all are of this type (Kobayashi 2015). The earliest remains of logboats in East Asia are dated to 8000-7500 cal BC in China, Korea and Japan (Figure 3; Jiang \& Liu 2005; Lee 2014; Okimatsu \& Hattori 2015). Whether these Early Holocene examples represent the earliest use of logboats in East Asia, however, is uncertain. Polished stone axes, which could be used to hew a logboat, existed from the beginning of the Jomon period (16 $000 \mathrm{cal} \mathrm{BP).} \mathrm{A} \mathrm{simpler} \mathrm{form} \mathrm{of} \mathrm{such} \mathrm{tools} \mathrm{-} \mathrm{the} \mathrm{edge-ground} \mathrm{stone} \mathrm{axe-has} \mathrm{an} \mathrm{even}$ longer history in Japan (Figure 4), with the oldest examples dating to c. $38000 \mathrm{cal} \mathrm{BP}$ (Habu 2010; Tsutsumi 2012).

While simpler watercrafts, such as floats and rafts, may also have been used in East Asian prehistory, there is currently no evidence for them. Planked boats of a more complex nature

(C) Antiquity Publications Ltd, 2019 


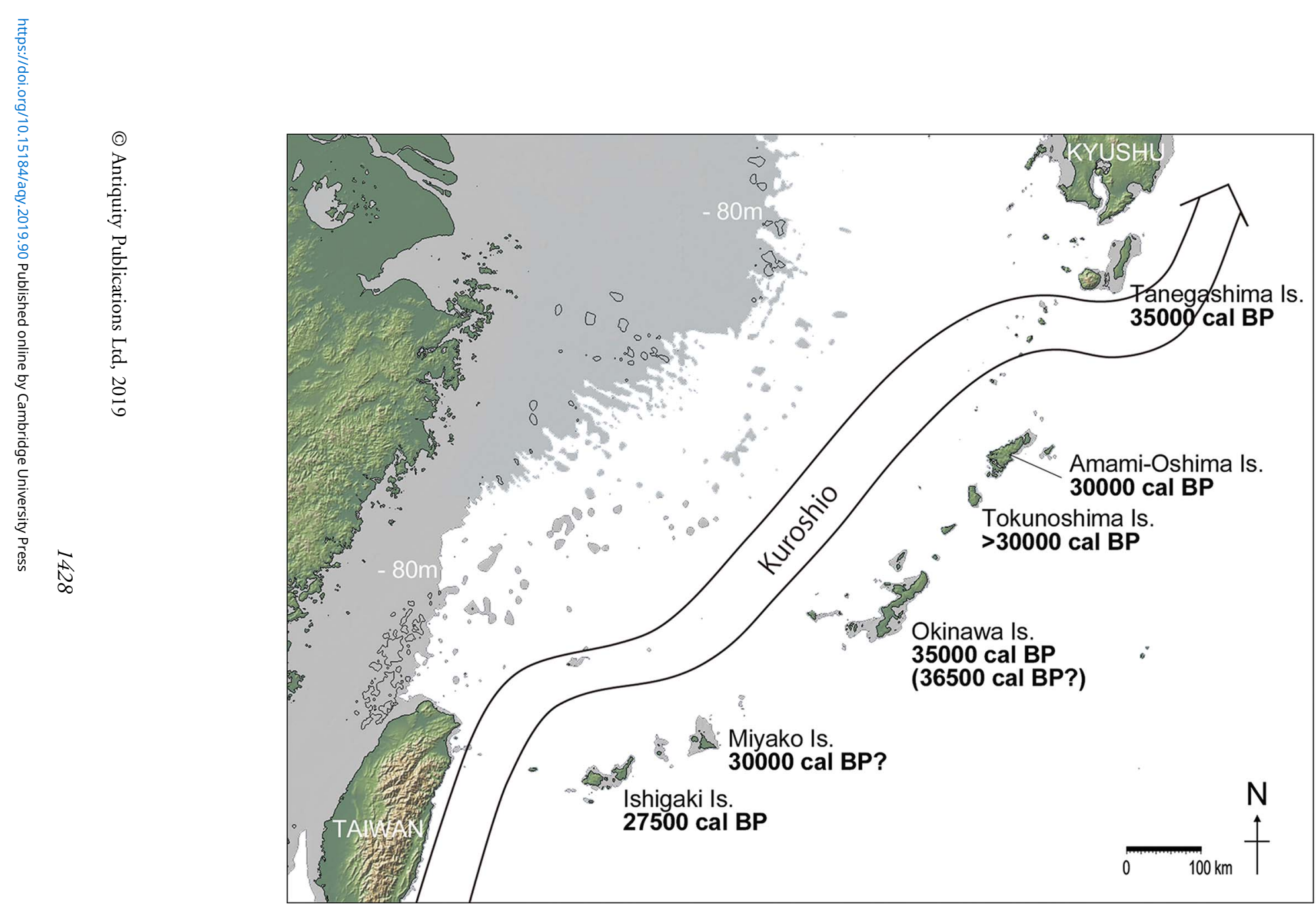

Figure 2. Palaeogeography of the Ryukyu Islands around the time of initial colonisation, reconstructed by lowering the sea level $80 \mathrm{~m}$ from that of the present day (grey areas). The map approximates the maximum land available 40-30 kya, when the fluctuating sea level was sometimes as much as 90m below modern levels (Yokoyama \& Esat 2011). The course of the present-day Kuroshio Current is shown, along with the oldest dates reported for Pleistocene sites (figure created using the GeoMapApp software (http://www. geomapapp.org)). 


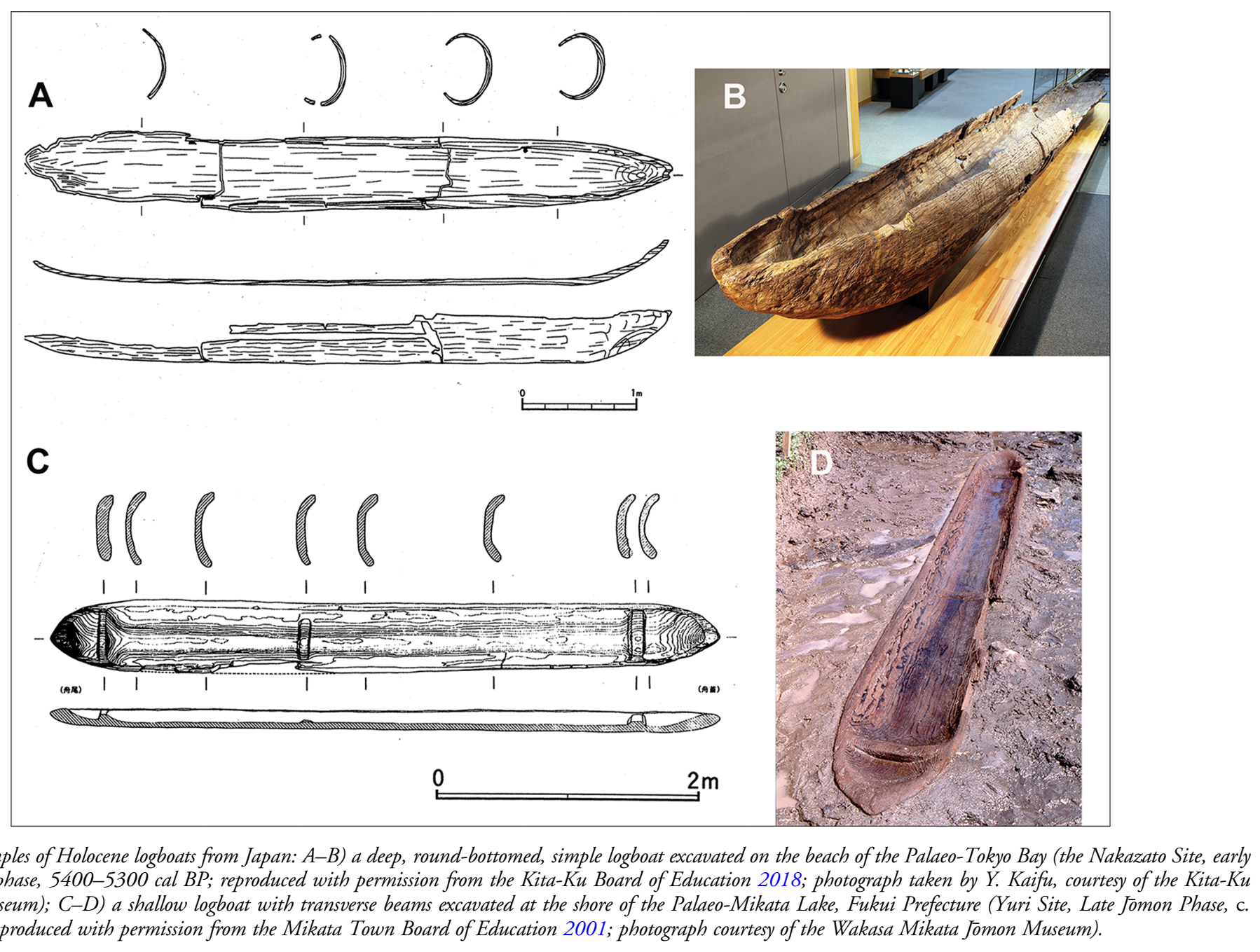

Figure 3. Examples of Holocene logboats from Japan: A-B) a deep, round-bottomed, simple logboat excavated on the beach of the Palaeo-Tokyo Bay (the Nakazato Site, early Middle Jomon phase, 5400-5300 cal BP; reproduced with permission from the Kita-Ku Board of Education 2018; photograph taken by Y. Kaifu, courtesy of the Kita-Ku Asukayama Museum); C-D) a shallow logboat with transverse beams excavated at the shore of the Palaeo-Mikata Lake, Fukui Prefecture (Yuri Site, Late Jomon Phase, c. 3900 cal BP; reproduced with permission from the Mikata Town Board of Education 2001; photograph courtesy of the Wakasa Mikata Jomon Museum).

\section{Research}



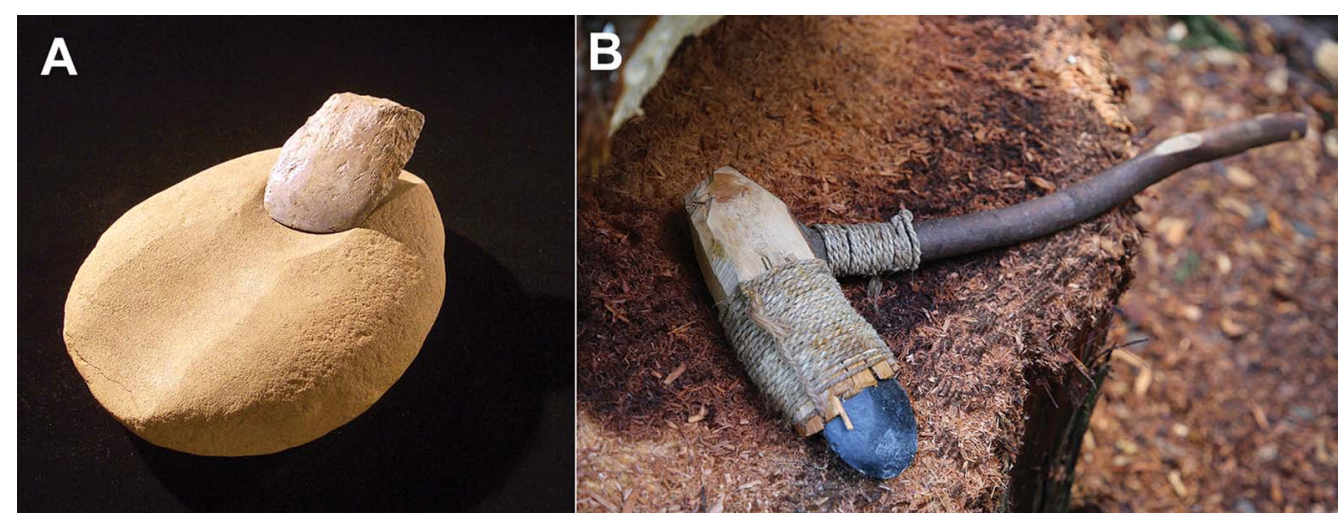

Figure 4. Possible wood-working tools from Japan: $A$ ) an edge-ground stone axe and a grind stone from the Kan-noki and Hinatabayashi B sites, Nagano Prefecture (c. 35000 cal BP; Archaeological Research Center of Nagano Prefecture 2000a \& b) (photograph taken by Y. Kaifu, courtesy of the Nagano Prefectural Museum of History); B) a replicated Palaeolithic edge-ground stone axe used in our experiments (photograph by Y. Kaifu).

were introduced to Japan, probably from China, after the Jōmon period (Habu 2010). Jōmon logboats were propelled by paddles, not by sails. Evidence for sailing, such as masts or rigging, has not been identified in association with any of the known Jōmon logboats discovered to date. Depictions or models of boats from late prehistoric to seventh-century AD Japanese contexts are also limited to paddling or rowing vessel types (Figure 5) (Yokota 2017), with the exception of one equivocal case from a first- to third-century AD context (Gifu Prefecture Cultural Conservation Center 1998). Although a number of wooden single-blade paddles have been discovered from Jōmon Japan (Fukazawa 2014), there is no evidence to suggest the presence of oars. The first evidence for the use of oars in Japan appears in the form of projections created at the gunwale of planked boats in the protohistoric Kofun period (third to sixth centuries AD).

Globally, sailing is regarded as a Holocene invention, with the oldest visual representation dating to c. $5000 \mathrm{BP}$ in Egypt; the earliest East Asian evidence-ideograms from Chinadates to c. 3000 BP (Doran 1971; Johnstone 1980; McGrail 2001; Anderson 2010).

Until recently, logboats were extensively used by Japanese fishermen at sea throughout the archipelago (Deguchi 1995). In contrast, ethnographic examples from Taiwan show that logboat use is limited to inland waters. Bamboo rafts, with or without a sail, represent the most commonly used seagoing vessel type in the coastal waters of Taiwan in the recent past (McGrail 2001). One exception is the use of seagoing logboats by the Tao (Yami) people of Orchid Island, although this practice may have been a later introduction from the south, as Tao are often related to Batan Islanders of the Philippines (Yang 2012).

The review presented here suggests that Palaeolithic crafts were propelled most probably by single-blade paddles, rather than by oars or sails. It also emphasises that evaluation of early seafaring should consider the use of both bamboo rafts and logboats.

\section{The sea of the Ryukyu Islands}

The maritime crossing to the $1200 \mathrm{~km}$-long Ryukyu island chain (Figure 2) must have been one of the most challenging undertaken during Marine Isotope Stage 3 (C) Antiquity Publications Ltd, 2019 


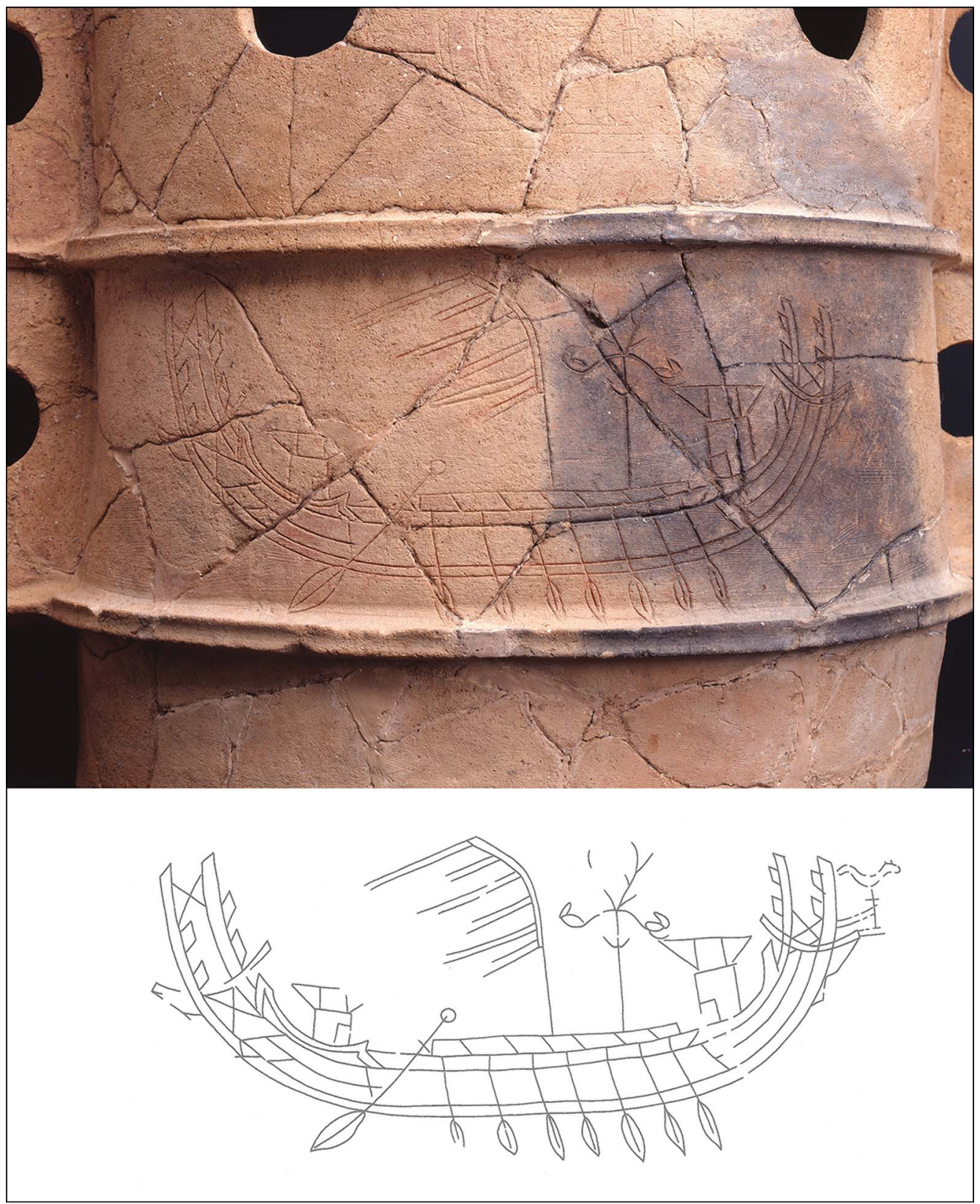

Figure 5. A third-to fourth-century AD earthenware from Japan depicting a planked rowing vessel with oars and a steering paddle (Higashitonozuka Kofun site; reproduced with permission from the Tenri City Board of Education 2000). The roofs, flag and other structures suggest that the boat is owned by aristocrats (photograph courtesy of the Tenri City Board of Education).

(Kaifu et al. 2015a). The islands are small, of low elevation and not all are intervisible with their neighbours. Moreover, one of the world's largest and strongest ocean currents, the Kuroshio, flows through the Yonaguni depression (around $800 \mathrm{~m}$ deep)

(C) Antiquity Publications Ltd, 2019 
separating Taiwan and Yonaguni Island (the westernmost island of the Ryukyus). Recent analyses of deep-sea cores and computer simulations demonstrate that, contrary to previous claims (Ujiié \& Ujiié 1999), the Kuroshio also followed this course during the Last Glacial Period. Hence, this current presented a major obstacle for Palaeolithic mariners - as it does to seafarers today (Ijiri et al. 2005; Lee et al. 2013; Kubota et al. 2017) (Figure 2). Indeed, Lee et al. (2013) use simulation studies to suggest that the Kuroshio was even faster in the Palaeolithic than it is at present. Further, fine-grained simulation studies are ongoing to investigate long-term temporal variation in the strength of the Kuroshio (X. Guo pers. comm.).

\section{Materials and methods}

\section{Building the bamboo rafts}

In order to build and test bamboo rafts, we looked to the east coast of Taiwan, where the local Amis tribe had a tradition of making such vessels for coastal fishing. Our aim was to evaluate the potential of the material, by building and testing rafts made from the most suitable bamboos used by the Amis people. An Amis craftsman, Laway, who learned the making of traditional bamboo rafts from elders, carried out the entire process-from material procurement to the construction of the rafts.

The bamboo species preferred by the Amis people for making rafts was 'Ma bamboo' (Dendrocalamus latiflorus Munro) (Liu et al. 2005). This species grows a thick culm (or stem) of up to $0.20 \mathrm{~m}$ in diameter, although the culm walls are generally thin $(>5 \mathrm{~mm})$ (Lin 2000) (Figure 6B). The large air cavities within the culm provide excellent buoyancy in water.

Bamboo can be cut and processed using simple stone tools (Bar-Yosef et al. 2012). Our own experiments have shown that large stone flakes from a type known from Palaeolithic contexts of the Baxiandong Caves in Taiwan (Tsang 2013) can cut a $0.15 \mathrm{~m}$-thick Ma bamboo culm within 20 minutes (Figure 6C).

The traditional Amis method of raft-making consists of harvesting suitable bamboos in autumn or winter, scraping off their outer skins, bending and straightening by fire, drying and, finally, assembly using rattan fibres (Calamus formosanus Becc.) with wooden battens. Metal tools were traditionally used for these processes (Liu et al. 2005).

For our rafts, we searched for especially thick Ma bamboo culms $(0.14-0.16 \mathrm{~m}$ diameter) across a wide area of Taiwan's east coast. Although we sought to follow the traditional Amis raft-making process as closely as possible, we were unable to peel the bamboo skin using stone tools. We did, however, bend the bamboo using heat, as there is ample evidence for Palaeolithic hearths in the Japanese archipelago, including the Ryukyu Islands. After confirming that each stage of construction can be completed using Palaeolithic technology (other than the skin peeling), we switched to metal tools to complete the experiment more swiftly.

In developing our designs, we assumed that Palaeolithic rafts could support several men and women, but were compact and light enough to be carried by a small group of people. Bednarik (1998, 1999), for example, constructed huge bamboo rafts (a 23m-long raft (C) Antiquity Publications Ltd, 2019 


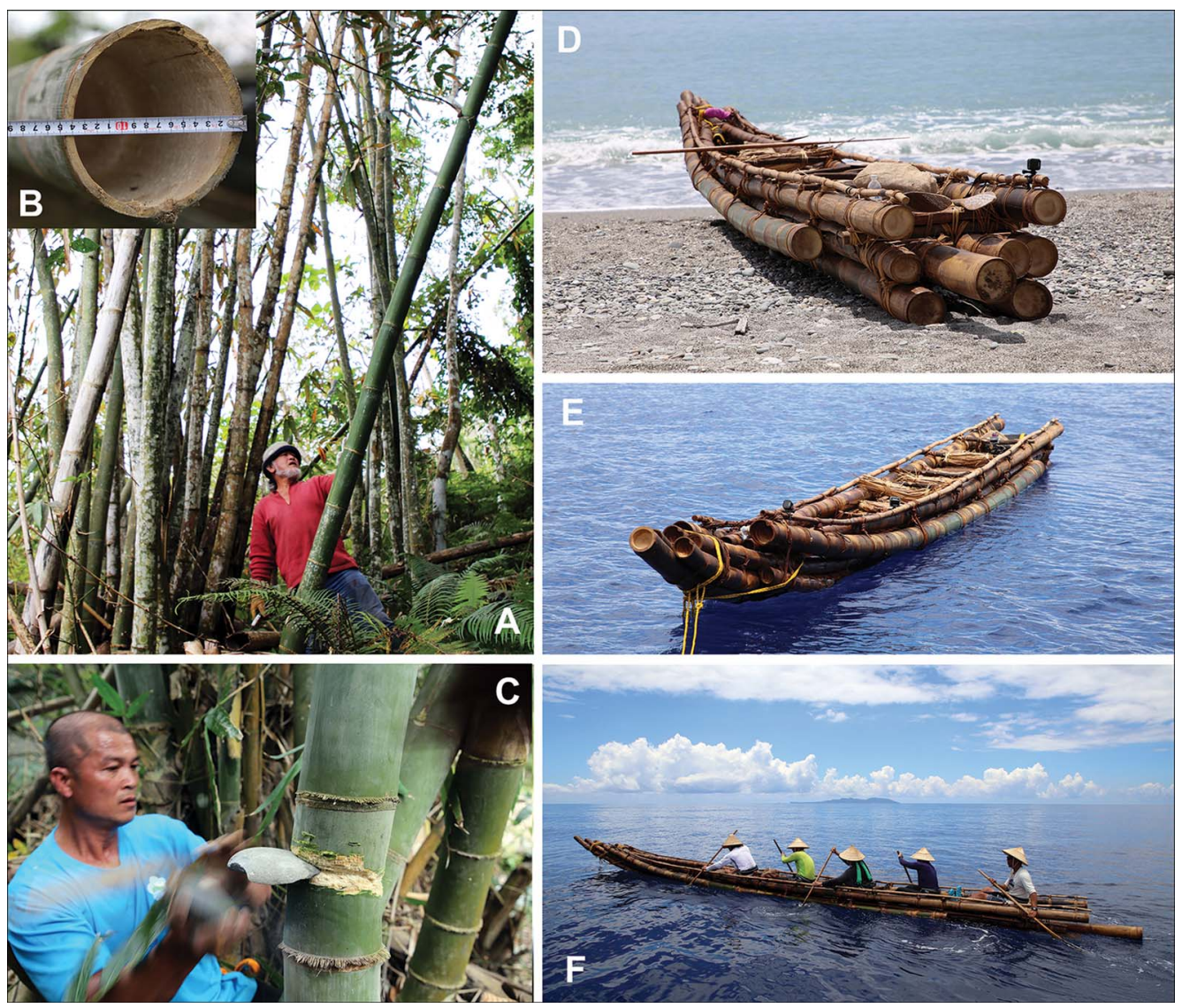

Figure 6. Experiments with the first bamboo raft, IRA 1: A) harvesting of bamboo materials in the coastal mountains; $B$ ) cross-section of a D. latiflorus culm; $C$ ) experimental cutting of a thick D. latiflorus using replica Palaeolithic stone tools; D) stern of IRA 1; E) bow of IRA 1; F) test at sea (all photographs by Y. Kaifu).

carried by 400 people, and a $18 \mathrm{~m}$-long raft weighing 2.8 tonnes) in his experimental research. Such heavy rafts could not be landed and reused, even if the voyage was successful. Rather than gambling on the success of a single voyage, we assume that prehistoric people used more durable and lightweight rafts that could be reused. To test the performance of these materials, we built and tested two rafts of different weights, buoyancy and shape (Figures 6-7).

The first raft, IRA 1, was made in 2017, based on a design that aimed to maximise speed (Figure 6). We used 11 thick bamboo culms assembled into a boat shape, with two culms aligned in parallel on the base of the craft to increase the buoyancy and to facilitate straight movement. Additional elements attached to the body included two thin bamboo culms for lifting handles, as well as mats of split bamboo and foot rests for the paddlers. The paddles were made with reference to the earliest excavated remains from Japan $(c .6000 \mathrm{cal} \mathrm{BP})$ using imported wood (Alaska cedar) and modern tools. The raft was $10.5 \mathrm{~m}$ long and $1 \mathrm{~m}$ wide, and although we could not measure its weight, approximately 10 people were needed to lift and move it.

(C) Antiquity Publications Ltd, 2019 

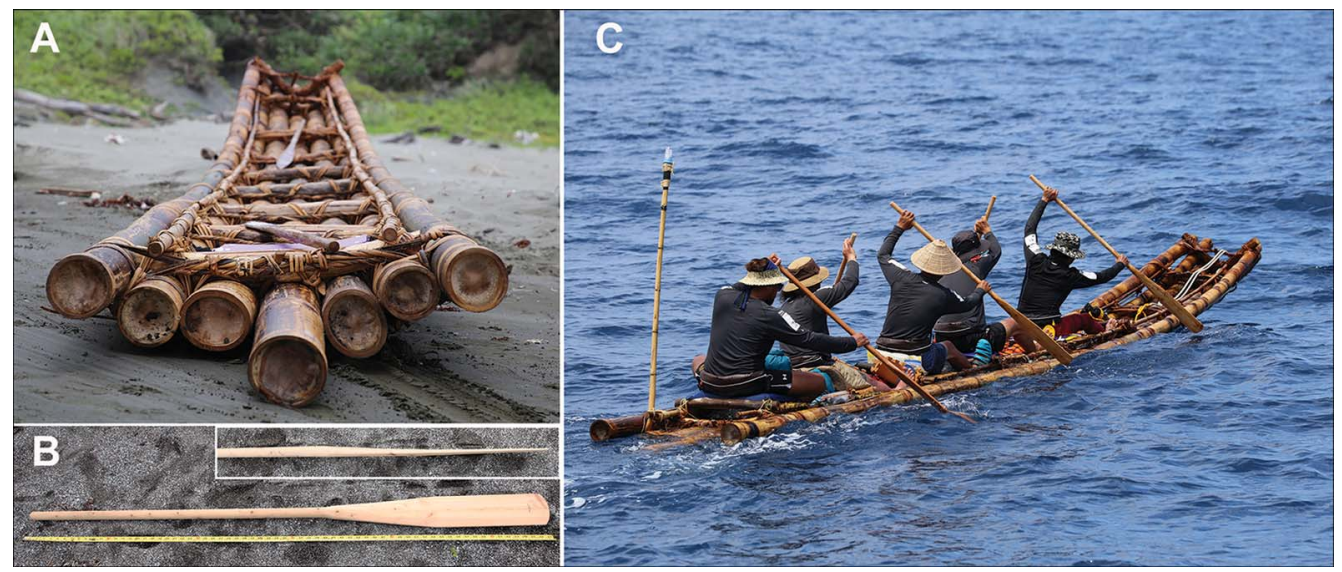

Figure 7. Experiments with the second bamboo raft, IRA 2: A) stern of IRA 2; B) paddle used; C) test at sea (all photographs by Y. Kaifu).

\section{Experimental voyage}

To conduct sea trials, we chose days with favourable weather, winds and swell. A major challenge for such experimental voyages has been uncertainty over ocean current conditions. Unlike winds and swells, current is invisible and difficult to detect from land; thus its potential influence on experimental craft has been almost impossible to evaluate. We address this problem by using the supercomputer-based ocean current simulator JCOPE-T (http://www. jamstec.go.jp/jcope/vwp/) (Varlamov et al. 2015). Using observation data of sea-surface elevation, temperature and salinity, together with data on wind, heat and tidal forces, this state-of-the-art system reconstructs and visualises ocean-current conditions on the selected test days on an hourly basis (rather than a daily mean), at both high resolution ( $3 \mathrm{~km}$ mesh size) and high precision. After each experimental voyage, we obtained hourly current maps produced by JCOPE-T. We superimposed the GPS track of the tested craft onto each map, and assessed the effects of the fluctuating current on the performance (i.e. the direction and speed) of the craft. Having such high-resolution and hourly data is important, as ocean currents sometimes change dramatically within a few hours (Figure 8); such changes could have significant implications for Palaeolithic seafarers.

Our watercraft were paddled by professional or semi-professional sea kayakers-both male and female — under the assumption that the Upper/Late Palaeolithic maritime migrants were experienced seafarers.

\section{Results}

Early on the morning of 11 June, 2017, IRA 1 departed on its test voyage from the shore at the town of Dawu (Figure 8). Four male and one female paddlers were on board, together with their belongings (e.g. paddles, drinking water and food). The destination was Green Island (Figure 8), located in the middle of the Kuroshio Current. Our navigation plan was that IRA 1 should head south-eastward so that we might assess how far the craft could move eastward while drifting northward, driven by the Kuroshio.

(C) Antiquity Publications Ltd, 2019 

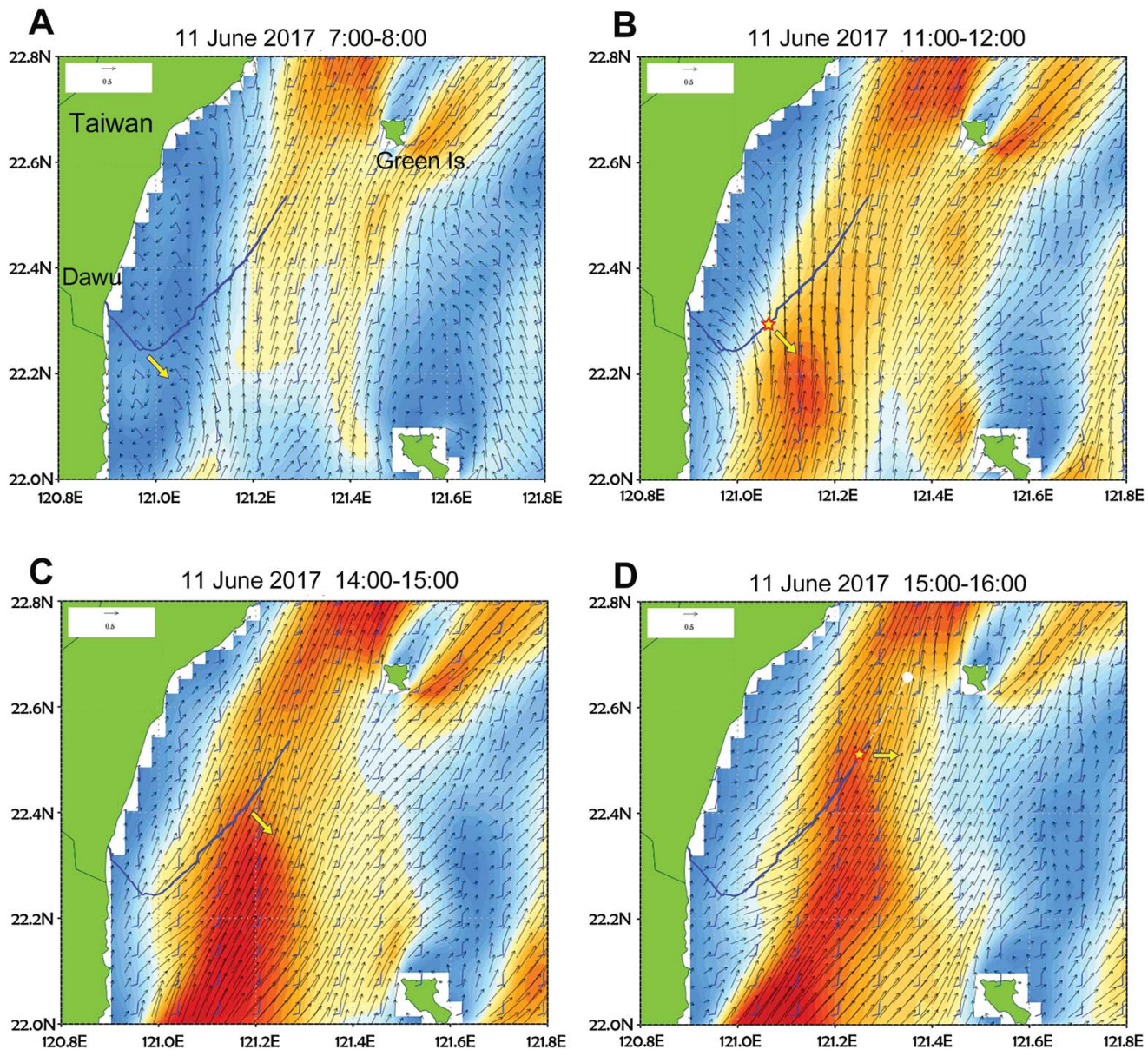

$\begin{array}{lllllllllllll}0.14 & 0.29 & 0.43 & 0.57 & 0.71 & 0.86 & 1.00 & 1.14 & 1.29 & 1.43 & 1.57 & 1.71 & 1.86(\mathrm{~m} / \mathrm{s})\end{array}$

Figure 8. GPS tracks of IRA 1 mapped on the hourly current models. The date and time are indicated on top of each chart; the location and travelling direction of the watercraft being tested are indicated by the yellow star and arrowhead, respectively; the blue symbols indicate wind speed and direction (images produced by JCOPE-T (http://www.jamstec.go. jp(jcopelvwp)).

With reference to the data derived from JCOPE-T, the performance of IRA 1 can be summarised as follows. In the coastal water outside the Kuroshio, with a flow less than $0.5 \mathrm{~m} / \mathrm{s}$ and a wind speed of approximately $2.5 \mathrm{~m} / \mathrm{s}, I R A 1$ was able to move as planned (Figure $8 \mathrm{~A}$ ). The cruising speed of IRA 1 , as estimated from speed data in this relatively calm water, was around $0.83 \mathrm{~m} / \mathrm{s}$ (1.62 knots). At the edge of Kuroshio, IRA 1 began to move diagonally northeastward under the influence of the strong northward flow (flow speed approximately $1 \mathrm{~m} / \mathrm{s}$ ) and the weak southerly (north-blowing) wind (approximately $2.5 \mathrm{~m} / \mathrm{s}$ ) (Figure 8B). As IRA 1 moved into the stronger part of the Kuroshio (flow speed around $1.5 \mathrm{~m} / \mathrm{s}$ ), the paddlers gradually lost control and could not move any farther eastwards (the craft moved towards the direction of $14^{\circ}$ relative to the Kuroshio flow; Figure 8C-D). After 14 hours and $80 \mathrm{~km}$ of

(C) Antiquity Publications Ltd, 2019 
paddling, we gave up our test voyage at a location $10 \mathrm{~km}$ west of Green Island (white circle in Figure $8 \mathrm{D}$ ). Strengthening southerly winds (approximately $5-8 \mathrm{~m} / \mathrm{s}$ ) also affected the craft's performance towards the end of the voyage.

Another problem we experienced was cracking. During a training period before the test voyage, we discovered a number of both large and small cracks on the bamboo culms. These cracks induced waterlogging, substantially diminishing buoyancy. Although we sealed major cracks before our test voyage, complete drainage of the culms was impossible without drilling holes. The slow speed of IRA 1 relative to the Kurohio may have resulted from its weight, coupled with the large surface area of the underside, which increases friction as the raft moved through the water.

Building upon the experience and knowledge gained from our first test, in 2018, we built a second bamboo raft, IRA 2 (Figure 7). This new raft was constructed using seven thick bamboo culms assembled in a traditional, mat-shaped raft resembling those made by the Amis. The craft was $9 \mathrm{~m}$ long and $1 \mathrm{~m}$ wide. As the blades of the previous paddles (Figure 6B) had proven too small to propel a heavy vessel effectively, we made new paddles for this test (Figure 7B). The new design and the new paddles, however, did not improve the situation. IRA 2 barely supported five paddlers (Figure $7 \mathrm{C}$ ) and the cruising speed measured in calm water was only $0.79 \mathrm{~m} / \mathrm{s}(1.53 \mathrm{knots})$.

\section{Discussion}

\section{The bamboo model}

Our two experimental bamboo raft designs made use of the most suitable bamboo species found in insular East Asia. Neither of the rafts, however, showed sufficient speed and endurance to navigate in the Kuroshio Current effectively. The buoyancy of D. latiflorus cannot be expected of other bamboo species available in the Japanese Archipelago; the culms of other indigenous and cultivated bamboo species grow to less than $0.12 \mathrm{~m}$ in diameter. A single exception is Phyllostachys edulis (Carrière) J.Houz., which has a thick culm of up to $0.24 \mathrm{~m}$ in diameter. Historical records, however, suggest that this species was introduced from China in the eighteenth century AD (Suzuki 1996). As Taiwan is currently the northern limit of the natural distribution of D. latiflorus, its local availability in the colder climate of the Late Pleistocene is doubtful. It follows that any rafts made of the bamboo species available during the Palaeolithic would have been even less seaworthy than our experimental rafts.

Moreover, these bamboo crafts seem to lack durability as evidenced by cracking caused by dehydration and insect damage. Local Amis people have developed various methods to mitigate these problems, such as harvesting in the dry season, removal of the outer skin of the culms, slow drying in beach sand and infiltration of ash mixed with water (Liu et al. 2005). According to Amis elders, perfectly treated bamboos can be used for up to five fishing seasons (approximately four months per year) if properly maintained by untying and drying the culms in the shade during the off-season. We found that at least one of the above processes, namely, removal of the culm's outer skin, is impossible without use of a metal blade. Bednarik's (1998) experimental study also reports substantial insect damage and cracking of the bamboo materials.

(C) Antiquity Publications Ltd, 2019 


\section{Other models}

In reference to the Early Holocene evidence, we assumed that the Palaeolithic East Asian seagoing crafts were either logboats or more rudimentary rafts. Although ethnographic reports from Asia and Oceania (e.g. Davidson 1935; McGrail 2001) describe various other potential construction materials, most of them are probably not relevant for the Palaeolithic.

Reed- or bark-bundle rafts are more perishable and of limited seaworthiness compared to a bamboo raft (Davidson 1935; McGrail 2001). The ethnographically documented use of bark boats in Australia, South America, Siberia and northern Japan are restricted to inland and coastal waters (Hornell 1946; Edwards 1972; Deguchi 1995). Similarly, hide boats are also limited to rivers and lakes in low to mid latitudes (India, China, Korea, and North and South America: Hornell 1946; McGrail 2001). Basket boats woven with strips of split bamboo are used extensively on the rivers and off the coast of Vietnam, although they travel no farther than approximately $4 \mathrm{~km}$ from shore (McGrail 2001). To our knowledge, the

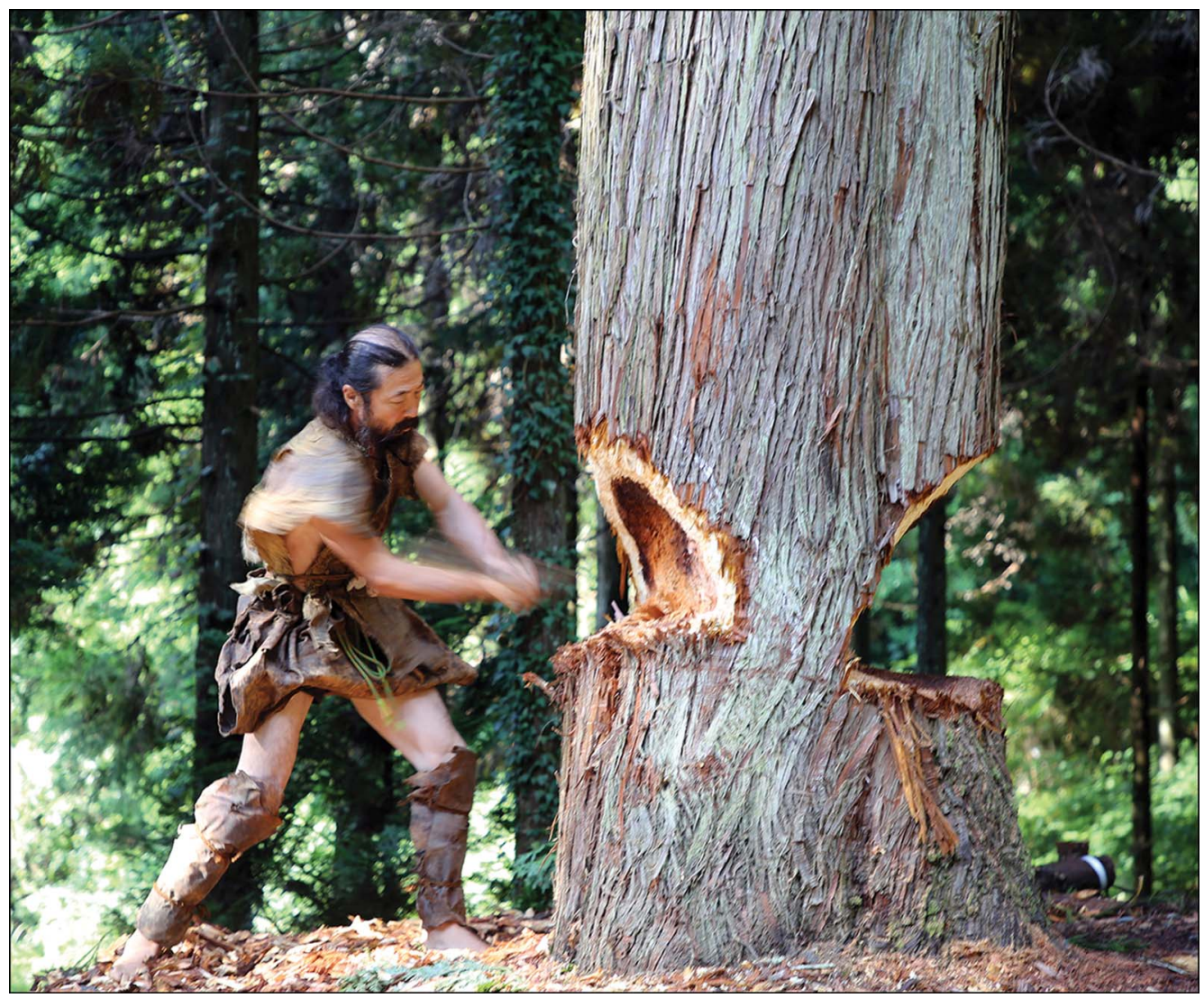

Figure 9. Experimental cutting on a 1m-thick Japanese cedar tree using the replica Palaeolithic edge-ground stone axe shown in Figure 4B. The test was conducted in 2017 on the Noto Peninsula in Honshu, Japan (photograph by Y. Kaifu).

(C) Antiquity Publications Ltd, 2019 
bitumen and other similar materials, such as coal tar used for waterproofing Vietnamese basket boats, is not naturally available in Taiwan and the Ryukyu Islands. While log rafts may be more durable than bamboo rafts, it is bamboo, not wood, that is the choice material for raftmaking by local fishermen traversing the coastal waters of the South China Sea. This is perhaps unsurprising, given the straightness, smoothness and buoyancy of bamboo, as well as its fast growth rate and wide availability.

If our research demonstrates that the use of seagoing bamboo rafts was improbable in Palaeolithic East Asia, what are the alternative possibilities? Our next step is to evaluate the logboat model; we have recently confirmed that a Palaeolithic-type edge-ground stone axe can cut down a large tree suitable for boat construction (Figure 9). A logboat can be made by burning and scraping with simple stone or shell tools, as ethnographically documented in North America (McGrail 2001), although such an endeavour becomes more efficient with the use of polished stone axes. Notably, such tools are now known to date back to the beginning of human activity in two insular regions of the Western Pacific: Australia (>47 000 cal BP; Hiscock et al. 2016; Clarkson et al. 2017) and Japan (c. 38000 cal BP; Tsutsumi 2012). Indeed, we have recently made a logboat using such stone tools, demonstrating that it can cross the Kuroshio and voyage from Taiwan to Yonaguni Island (Normile 2019; Servick 2019).

Despite the lack of direct material evidence, experimental archaeology, when coupled with other lines of evidence such as ethnographic knowledge and computer simulation, can illuminate questions about Palaeolithic seafaring and the movement of humans into new environments. Further developments in this field will provide unique information about the capability of different types of watercraft; the speed and time needed for maritime travel; the technology, knowledge and resources required for construction; and the levels of energy invested by early human societies in exploring new habitats.

\section{Acknowledgements}

We thank Masahiro Uchida, Yasuo Ihara, Jin Ishikawa, Hironobu Kan, Yasuhito Koike, Reiko Kono, Chiaki Katagiri, Goro Kokubugata, Hiroyuki Onishi, Rintaro Ono, Yoshiharu Sekino, Kenichi Shinoda, Yoshinori Suzawa, Yuji Tamura, Shinji Yamasaki, Yusuke Yokoyama, Minoru Yoneda, Kyoko Miyazawa, and Raiway and Kunihiro Amemiya for help with the experiments. We also thank Hiroyuki Sato, Yoshiyuki Iizuka, and Koji Tsukamoto for helpful comments, and staff of the National Museum of Nature and Science, Tokyo, and National Museum of Prehistory, Taitung, for their support with the experimental project. This work was supported by JSPS KAKENHI (grant number JP18H03596); the National Museum of Nature and Science, Tokyo; 1752 crowdfunding supporters, and other countless donors; Japan Airlines Co., Ltd; Nippon Express Co., Ltd; Best World Corporation; Lumine Co., Ltd; World Brains Co., Ltd; Valley of Gangala, Nanto Co., Ltd; Pharmarise Holdings Corporation; MCG Inc.; HIT Corporation; Ikari Shodoku Co., Ltd; Montbell Co., Ltd; Sansou Systems Co., Ltd; Shin Kong International Securities Co., Ltd; Cipherlab Co., Ltd; and HarleyDavidson Motor Co.

\section{References}

Anderson, A. 2010. The origins and development of seafaring: towards a global approach, in A. Anderson, J.H. Barrett \& K.V. Boyle (ed.) The global origins and development of seafaring. 3-16.
Cambridge: McDonald Institure for Archaeological Research.

Archaeological Research Center of Nagano Prefecture. 2000a. Hinatabayashi B Iseki. Nagano: Archaeological Research Center of Nagano Prefecture (in Japanese).

(C) Antiquity Publications Ltd, 2019 
- 2000b. Kan-noki Site. Nagano: Archaeological Research Center of Nagano Prefecture (in Japanese).

Bar-Yosef, O., M.I. Eren, J. Yuan, D.J. Cohen \& Y. LI. 2012. Were bamboo tools made in prehistoric Southeast Asia? An experimental view from south China. Quaternary International 269: 9-21. https://doi.org/10.1016/j.quaint.2011.03.026

BednariK, R.G. 1998. An experiment in Pleistocene seafaring. International Journal of Nautical Archaeology 27: 139-49. https://doi.org/10.1016/S1057-2414(98)80070-8

- 1999. Nale Tasih 2: journey of a Middle Palaeolithic raft. International Journal of Nautical Archaeology 28: 25-33.

https://doi.org/10.1111/j.1095-9270.1999. tb00819.x

BIRDSELL, J.B. 1977. The recalibration of a paradigm for the first peopling of greater Australia, in J. Allen, J. Golson \& R. Jones (ed.) Sunda and Sahul: prehistoric studies in Southeast Asia, Malaysia and Australia: 113-67. London: Academic.

Clarkson, C. et al. 2017. Human occupation of northern Australia by 65000 years ago. Nature 547: 306-10. https://doi.org/10.1038/nature22968

DAvidson, D.S. 1935. The chronology of Australian watercraft. Journal of the Polynesian Society and Natural Resources 44: 1-16.

Deguchi, A. 1995. Traditional watercrafts in Japan and neighboring regions of Asia: a cultural geographic study. Tokyo: Bunken Shuppan (in Japanese).

Doran, E.J. 1971. Sailing raft as a great tradition, in C.L. Riley, J.C.L. Kelley, C.W. Pennington \& R.L. Rands (ed.) Man across the sea: 115-38. Austin: University of Texas Press.

EDWARDs, R. 1972. Aboriginal bark canoes of the Murray Valley. Adelaide: Rigby for the South Australian Museum.

Erlandson, J.M. \& T.J. Braje. 2015. Coasting out of Africa: the potential of mangrove forests and marine habitats to facilitate human coastal expansion via the Southern Dispersal Route. Quaternary International 382:

31-41.

https://doi.org/10.1016/j.quaint.2015.03.046

ErLandson, J.M. et al. 2011. Paleoindian seafaring, maritime technologies, and coastal foraging on
California’s Channel Islands. Science 331: 118185. https://doi.org/10.1126/science. 1201477

FukAZAWA, Y. 2014. Inventory of unearthed materials associated with boats and ships in prehistoric and ancient Japan, in A. Goto (ed.) International Center for Folk Culture Studies monograph 5: comparative research on traditional boat-building techniques around the Pacific Rim: 185-233. Kanagawa: International Center for Folk Culture Studies (in Japanese).

Gifu Prefecture Cultural Conservation Center. 1998. Araominami site. Excavation report of the Gifu Prefecture Cultural Conservation Center 26. Gifu: Gifu Prefecture Cultural Conservation Center (in Japanese).

Habu, J. 2010. Seafaring and the development of cultural complexity in Northeast Asia: evidence from the Japanese Archipelago, in A. Anderson, J.H. Barrett \& K.V. Boyle (ed.) The global origins and development of seafaring. Cambridge: McDonald Institute for Archaeological Research.

Hiscock, J., S. O'Connor, J. Balme \& T. Maloney. 2016. World's earliest ground-edge axe production coincides with human colonisation of Australia. Australian Archaeology 82: 2-11. http://doi.org/10.1080/03122417.2016. 1164379

Hornell, J. 1946. Water transport: origins and early evolution. Cambridge: Cambridge University Press.

Ijiri, A., L. Wang, T. Oba, H. Kawahata, C.-Y. Huang \& C.-Y. Huang. 2005.

Paleoenvironmental changes in the northern area of the East China Sea during the past 42000 years. Palaeogeography, Palaeoclimatology, Palaeoecology 219: 239-61. https://doi.org/10.1016/j.palaeo.2004.12.028

IKEYA, N. 2015. Maritime transport of obsidian in Japan during the Upper Paleolithic, in Y. Kaifu, M. Izuho, T. Goebel, H. Sato \& A. Ono (ed.) Emergence and diversity of modern human behavior in Paleolithic Asia. College Station: Texas A\&M University Press.

JiAnG, L. \& L. Liu. 2005. The discovery of an 8000 -year-old dugout canoe at Kuahuqiao in the Lower Yangzi River, China. Antiquity Project Gallery 79(305).

Johnstone, P. 1980. The sea-craft of prehistory. Cambridge (MA): Harvard University Press. 
Kaifu, Y., M. Izuho \& T. Goebel. 2015a. Modern human dispersal and behavior in Paleolithic Asia: summary and discussion, in Y. Kaifu, M. Izuho, T. Goebel, H. Sato \& A. Ono (ed.) Emergence and diversity of modern human behavior in Paleolithic Asia: 535-66. College Station: Texas A\&M University Press.

Kaifu, Y., M. Fujita, M. Yoneda \& S. Yamasaki. 2015b. Pleistocene seafaring and colonization of the Ryukyu Islands, southwestern Japan, in Y. Kaifu, M. Izuho, T. Goebel, H. Sato \& A. Ono (ed.) Emergence and diversity of modern human behavior in Paleolithic Asia: 345-61. College Station: Texas A\&M University Press.

Kealy, S., J. Louys \& S. O’Connor. 2018. Least-cost pathway models indicate northern human dispersal from Sunda to Sahul. Journal of Human Evolution 125: 59-70. https://doi.org/10.1016/j.jhevol.2018.10.003

Kita-Ku Board of Education. 2018. Nakazato site. Tokyo: Kita-Ku Board of Education (in Japanese).

Kobayashi, K. 2015. Research status of the Jomon logboats: current situation and prospects, in Chuo University (ed.) History of islands and harbor: 3-39. Tokyo: Chuo University Press (in Japanese).

Kubota, Y., N. Suzuki, K. Кimoto, M. Uchida, T. Itaki, K. Ikehara, R.A. Kim \& K.E. Lee. 2017. Variation in subsurface water temperature and its link to the Kuroshio Current in the Okinawa Trough during the last $38.5 \mathrm{kyr}$. Quaternary International 452: 1-11. https://doi.org/10.1016/j.quaint.2017.06.021

LEE, S. 2014. On a logboat excavated from Bibong-ri shell mound site, South Korea. Bulletin of the Laboratory of Archaeology, the University of Tokyo 28: 159-86.

Lee, K.E., H.J. Lee, J.-H. Park, Y.-P. Chang, K. Ikehara, T. Itaki \& H.K. Kwon. 2013. Stability of the Kuroshio path with respect to glacial sea level lowering. Geophysical Research Letters 40: 392-96. https://doi.org/10.1002/grl.50102

LIN, W.-C. 2000. Bambusoideae, in D. Bufford, C.-F. Hsieh, T.-C. Huang, C.-S. Kuoh, H. Ohashi \& H.-J. Su (ed.) Flora of Taiwan: 589-54. Taipei: The Editorial Committee of the Flora of Taiwan.

Liu, C., C. KaO, J.-Z. Lin \& H.-C. ChaO. 2005. Bamboo raft and fishery culture of the Amis
Indigenous people on the eastern coast of Taiwan. Taitung: Austronesian Community College Association of Taitung County.

McGrail, S. 2001. Boats of the world: from the Stone Age to medieval times. Oxford: Oxford University Press.

Mikata Town Board of Education. 2001. Yuri site. Excavation report of the Mikata City Cultural Property Research, 14. Fukui: Mikata Town Board of Education (in Japanese).

O’Connell, J.F., J. Allen, M.A.J. Williams, A.N. Williams, C.S.M. Turney, N.A. Spooner, J. Kamminga, G. Brown \& A. Cooper. 2018. When did Homo sapiens first reach Southeast Asia and Sahul? Proceedings of the National Academy of Sciences of the USA 115: 8482-90. https://doi.org/10.1073/pnas.1808385115

O'Connor, S. 2010. Pleistocene migration and colonization in the Indo-Pacific region, in A. Anderson, J.H. Barrett \& K.V. Boyle (ed.) The global origins and development of seafaring: 41-55. Cambridge: McDonald Institute for Archaeological Research.

Oda, S. 2000. Archaeology of the Kuroshio area. Tokyo: Daiichi-shobo (in Japanese).

Okimatsu, N. \& T. Hattori. 2015. Kaminarishita site in Chiba prefecture (earliest evidence for the dugout in Japan). The Archaeological Journal 671: 29-32 (in Japanese).

Normile, D. 2019. Update: explorers successfully voyage to Japan in primitive boat in bid to unlock an ancient mystery. Available at:

https:/www.sciencemag.org/news/2019/07/ explorers-voyage-japan-primitive-boat-hopesunlocking-ancient-mystery (accessed 22 October 2019).

Phoca-Cosmetatou, N. \& R.J. Rabett. 2014.

Pleistocene island occupation in the Mediterranean: insights from a tied-biome approach to glacial refugia, in K.V. Boyle, R.J. Rabett \& C.O. Hunt (ed.) Living in the landscape: essays in honour of Graeme Barker: 83-108. Cambridge: McDonald Institute for Archaeological Research.

Servick, K. 2019. Paddlers to replicate ancient voyage. Science 365: 10-11. https://doi.org/10.1126/science.365.6448.10

SEverin, T. 1994. The China voyage. London: Little, Brown \& Company. 
Shinoda, K. \& N. Adachi. 2013. DNA analyses of the human skeletal remains from the Shiraho-Saonetabaru Cave site, in Okinawa Prefectural Archaeological Center (ed.) Shiraho-Saonetabaru cave site: excavation report of the Okinawa Prefectural Archaeological Center 65: 219-28. Okinawa: Okinawa Prefectural Archaeological Center (in Japanese).

Suzuki, S. 1996. Illustrations of Japanese Bambusaceae. Chiba: Jyukaishorin (in Japanese).

Tenri City Board of Education. 2000. Nishitonozuka Kofun, Higashitonozuka Kofun. Excavation report of the Tenri City Buried Cultural Property Research Center, 7. Nara: Tenri City Buried Cultural Property Research Center (in Japanese).

Thorne, A. \& R. Raymond. 1989. Man on the Rim: the peopling of the Pacific. Angus: North Ryde.

TsANG, C.-H. 2013. New archaeological discoveries at Baxiandong and the issues related to the chronology and the affinities of the Palaeolithic Culture in Taiwan, in K.-T. Chen \& C.-H. Tsang (ed.) New discoveries in East Asian archaeology: 341-49. Taipei: Institute of History and Philology, Academia Sinica.

Tsutsumi, T. 2012. MIS3 edge-ground axes and the arrival of the first Homo sapiens in the Japanese archipelago. Quaternary International 248: 70-78. https://doi.org/10.1016/j.quaint.2011.01.030

UjıIÉ, H. \& Y. UJIIÉ. 1999. Late Quaternary course changes of the Kuroshio Current in the Ryukyu Arc region, north-western Pacific Ocean. Marine Micropaleontology 37: 23-40. https://doi.org/10.1016/S0377-8398(99)00010-9

Varlamov, S.M., X. GuO, T. MiYama, K. IChiKawa, T. Waseda \& Y. Miyazawa. 2015. M2 baroclinic tide variability modulated by the ocean circulation south of Japan. Journal of Geophysical Research: Oceans 120: 3681-710. https://doi.org/10.1002/2015JC010739

YANG, C.-H. 2012. 'Ethnic group' existed betwixt and between islands and states: on oral histories among the Tao from Orchid Island, Taiwan and the Ivatan from Batanes Islands, the Philippines. Journal of Austronesian Studies 3: 27-53 (in Chinese).

Yокота, Y. 2017. Possibilities of sailing in ancient Japan. Kagaku 87: 859-64 (in Japanese).

Yoкоyama, Y. \& T.M. Esat. 2011. Global climate and sea level: enduring variability and rapid fluctuations over the past 150000 years. Oceanography 24: 54-69. https://doi.org/10.5670/oceanog.2011.27

Received: 20 February 2019; Revised: 14 May 2019; Accepted: 5 June 2019

(C) Antiquity Publications Ltd, 2019 